IZA DP No. 8848

Drug Decriminalization and the Price of Illicit Drugs

Sónia Félix

Pedro Portugal

February 2015

Forschungsinstitut zur Zukunft der Arbeit Institute for the Study of Labor 


\title{
Drug Decriminalization and the Price of Illicit Drugs
}

\author{
Sónia Félix \\ Nova School of Business and Economics \\ and Banco de Portugal \\ Pedro Portugal \\ Nova School of Business and Economics, \\ Banco de Portugal and IZA
}

\section{Discussion Paper No. 8848 \\ February 2015}

\author{
IZA \\ P.O. Box 7240 \\ 53072 Bonn \\ Germany \\ Phone: +49-228-3894-0 \\ Fax: +49-228-3894-180 \\ E-mail: iza@iza.org
}

Any opinions expressed here are those of the author(s) and not those of IZA. Research published in this series may include views on policy, but the institute itself takes no institutional policy positions. The IZA research network is committed to the IZA Guiding Principles of Research Integrity.

The Institute for the Study of Labor (IZA) in Bonn is a local and virtual international research center and a place of communication between science, politics and business. IZA is an independent nonprofit organization supported by Deutsche Post Foundation. The center is associated with the University of Bonn and offers a stimulating research environment through its international network, workshops and conferences, data service, project support, research visits and doctoral program. IZA engages in (i) original and internationally competitive research in all fields of labor economics, (ii) development of policy concepts, and (iii) dissemination of research results and concepts to the interested public.

IZA Discussion Papers often represent preliminary work and are circulated to encourage discussion. Citation of such a paper should account for its provisional character. A revised version may be available directly from the author. 
IZA Discussion Paper No. 8848

February 2015

\section{ABSTRACT}

\section{Drug Decriminalization and the Price of Illicit Drugs*}

This study is an empirical assessment of the impact of the drug decriminalization policy followed by Portugal in July, 2001. We investigate especially the impact of the policy change on the price of illicit drugs. The analysis is performed using a difference-in-differences approach and a comprehensive set of countries as control group. We also investigate the application of Synthetic Control Method in order to construct a synthetic control unit from a convex combination of other countries. The results suggest that the prices of opiates and cocaine in the post-treatment period did not decrease in the sequence of the policy change. This result contrasts with the argument that softer drug law enforcement necessarily leads to lower prices and, consequently, to higher drug usage rates and dependence.

JEL Classification: C21, D04

Keywords: $\quad$ illicit drugs, drug decriminalization policy, drug prices, treatment effects

Corresponding author:

Pedro Portugal

Banco de Portugal

Av. Almirante Reis, 71-6th floor

1150-165 Lisboa

Portugal

E-mail: pportugal@bportugal.pt

\footnotetext{
*We are grateful to Ana Tavares for her help with the data. Financial support from Fundação para a Ciência e Tecnologia is acknowledged. The views expressed are those of the authors and do not involve the responsibility of the Banco de Portugal or the Eurosystem.
} 
One moderate alternative to the war on drugs is to follow Portugal's lead and decriminalize all drug use while maintaining the illegality of drug trafficking.

by Gary S. Becker and Kevin M. Murphy (2013)

\section{Introduction}

The United Nations Office on Drug and Crime (UNODC) estimates that in 2009 between 172 million and 250 million people used illicit drugs and between 18 million and 38 million were drug dependent, worldwide. In fact, drug use and dependence is a major threat to global health, representing one of the top ten risk factors in the developed countries. The risk of contracting infectious diseases such as HIV, AIDS, Hepatitis, and Tuberculosis is higher for drug users than for nonusers.

The relevance of the social and economic costs implied by drug use and dependence contributes to the current hot debate on drug policy in many countries such as the United Kingdom, Australia, and the United States. Policymakers and economists have been discussing a comprehensive response to drug use and trafficking for decades but the solution is far from being unanimous. Furthermore, policymakers have been reluctant to reform drug laws.

The alternative law enforcement schemes that have been at the center of the debate are the illicit drugs legalization, decriminalization, and depenalization. Those terms are often misused. In this paper legalization is defined as the amendment of law to eliminate any sanction, criminal or administrative, associated with the possession, use, or distribution of any controlled drugs; decriminalization is defined as a new response to drug offenses through administrative processes (namely, community service, fines, suspension of professional lisences, among others) rather than through the criminal justice system; depenalization is defined as the end of criminal punishments associated with the possession, use, or distribution of drugs.

In the late 1980s and 1990s a growing population of intravenous heroin users became a major threat to public health in Portugal, with rates of heroin users among the highest in Europe. The number of HIV infections and drug related deaths rose dramatically. In the mid'90s Portugal engaged in a serious discussion on alternative enforcement policies to deal with drug use, and in 1998 a panel of leading academics 
and medical professionals were invited to study and propose a new national drugs strategy. The National Commission for the National Strategy to Combat Drugs elaborated a report with recommendations rooted in understanding drug dependency as a disease rather than a crime and proposing prevention, treatment, and reintegration programs as an alternative to prison. The recommendations of this panel of experts led to the adoption of the National Strategy for the Fight Against Drugs in 1999. The main recommendations encompass a new legal framework with the end of criminal sanctions for drugs users, the enforcement of law to reduce drug production and trafficking, and the expansion of policies and resources for the reintegration of drug users and treatment. Recognizing that illicit drug use and dependence was a major threat to public health, Portugal decided to adopt a health-led approach. The focus on treatment, care, and rehabilitation as an alternative to criminal punishment of drug users is intended to stabilize the demand while a more effective law enforcement targeting drug trafficking and production was designed to reduce the supply of illicit drugs.

This process culminated with the law reform decriminalizing the personal use and possession of illicit drugs on July 1, 2001 (Law 30/2000). The new law applies to the use, possession, or acquisition of all drugs, including "hard" drugs, in quantities up to a ten day supply ${ }^{1}$. Until this legislative change, the use, possession, or production of illicit drugs for personal use were criminally punishable by up to 1 year in prison or a fine, even though drug users rarely faced criminal sanctions, in practice. While the legal changes decriminalize drug use, possession, and acquisition they did not legalize any drug related offenses. Police can no longer arrest drug users but must refer them to the local Commissions for the Dissuasion of Drug Use (Comissões para a Dissuasão da Toxicodependência) (CDT) that decide the administrative or public order sanction to apply. Those commissions are three-member panels comprising social workers, lawyers, and medical professionals. Criminal penalties are still applied to drug traffickers.

The discussion on the alternative legislative approaches to deal with the illicit drug economy is centered on the idea that decriminalization leads to a price reduction and consequently to an increase in the prevalence of drug use. Recent empirical

\footnotetext{
${ }^{1}$ According to Decreto-Lei n 15/93, January 22, 1993 and Portaria n 94/96, March 26, 1996, this amounts to $0.1 \mathrm{~g}$ heroin, $0.1 \mathrm{~g}$ ecstasy, $0.1 \mathrm{~g}$ amphetamines, $0.2 \mathrm{~g}$ cocaine or $2.5 \mathrm{~g}$ cannabis.
} 
work by Williams (2004), Zhao and Harris (2004), and Damrongplasit, Hsiao, and Zhao (2010), shows a slight increase of drug use subsequent to drug decriminalization. Featherston and Lenton (2007) and Donnelly, Hall, and Christie (1995) find no significant association.

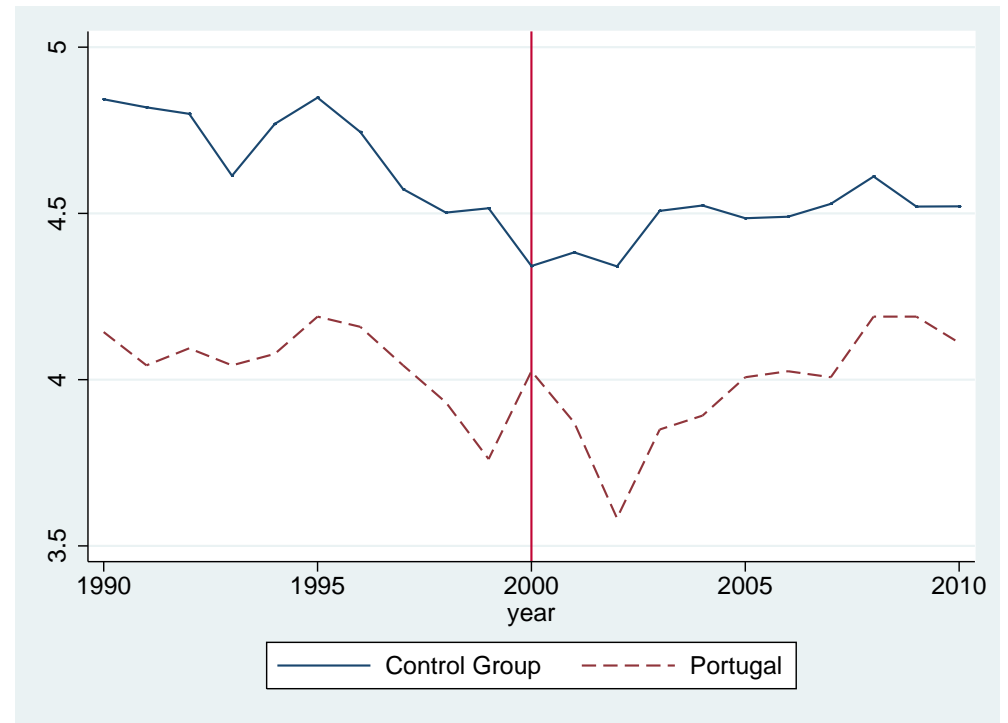

Figure 1 - Evolution of the logarithm of cocaine prices, 1990-2010 Notes: For detailed data definitions and sources see Appendix Table A1.

In this paper we shed further light on the impact of drug decriminalization on the illicit drug market by studying its impact on the price of illicit drugs. A primary reason to focus on the impact of the policy change on the price of drugs is the presumed effect of prices on use and consumption. Furthermore, it is crucial for policymakers to understand if there exists a causal relationship between drug decriminalization and lower prices when discussing the drug policy of the country. The fear of increased usage and dependence due to lower prices has led the discussion, but these arguments are speculative as no robust empirical evidence on the impacts of decriminalization on prices can be found in the literature. According to Figures 1 and 2 it seems reasonable to argue that there are no changes in the trends of cocaine and opiate prices after the policy change. If there is no causal effect, policymakers may adopt a less punitive behavior toward drug policy.

The current paper examines the dynamics of the illicit drugs market, focusing on the supply side of the market. To evaluate the impact of the policy change on prices 


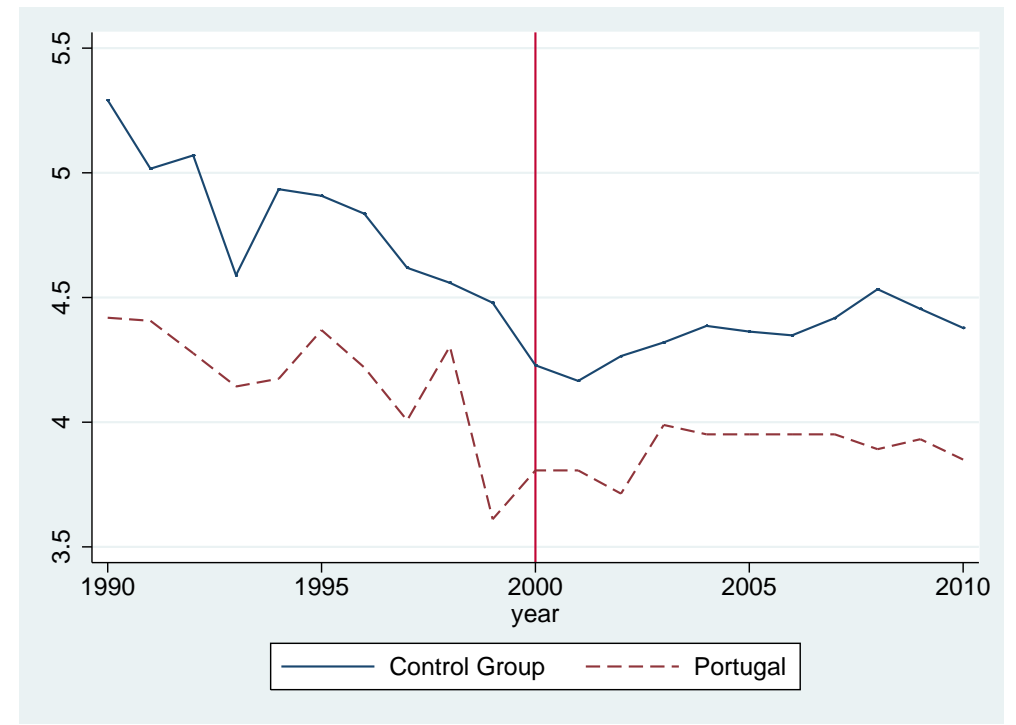

Figure 2 - Evolution of the logarithm of opiates prices, 1990-2010 Notes: For detailed data definitions and sources see Appendix Table A1.

we follow two empirical approaches. The first is a standard difference-in-differences analysis that allows controlling for observed and unobserved heterogeneity and time effects. The second approach is the application of the Synthetic Control Method, which has the advantage of providing a systematic way of constructing a comparison group that best resembles the characteristics of the treated unit.

This paper is organized as follows: Section 2 presents related literature. Section 3 introduces a simple theoretical model. Section 4 describes the data and the empirical methodology and discusses the results. Section 5 concludes.

\section{Related Literature}

The discussion of policy toward illicit drugs commonly uses the metaphor of markets to explain the dynamics of use. Even though prices play a crucial role in the metaphor they have been overlooked in the empirical analysis and data collection. In fact, prices constitute a prominent indicator for understanding the effects of a policy change such as drug decriminalization. In fact, the sharp decline of the retail prices of hard drugs like cocaine and heroin in the last 20 years (see Costa Storti and De Grawve (2009a) and Costa Storti and De Grawve (2009b)) highlights the importance of studying the 
mechanisms beyond public policies aimed at reducing the supply of illicit drugs.

Becker and Murphy (1988) present a model of rational addiction which implies that the consumption of addictive substances is likely to respond considerably to prices. Over the last decades some studies have focused on the price elasticity of demand of addictive licit substances, namely alcohol and tobacco. Becker, Grossman, and Murphy (1994) find substantial elasticity of demand for cigarettes in the short and long run (-0.4 and between -0.7 and -0.8 , respectively). Similar elasticities of demand for alcohol are reported by Coate and Grossman (1988).

Subsequently, this research was extended to the illicit drugs market. Economists have been focused on the price sensitivity of drug use, often using the prevalence as dependent variable. VanOurs (1995) uses data from the early twentieth century and estimates noticeable short- and long-run elasticities of demand for pre-World War II opium consumption in the Dutch East Indies (-0.7 and -1.0, respectively). Caulkins (1995) finds an elasticity of demand for cocaine between -1.5 and -2.0 for a very specific group of people, the arrestees. Saffer and Chaloupka (1999) find a price elasticity for the prevalence of heroin of -0.9 and for the prevalence of cocaine of -0.55. Grossman and Chaloupka (1998) find that cocaine consumption by American youth is very responsive to changes in its price. Also, the different legal approach to alcohol and marijuana is likely to explain different cocaine consumption among the U.S. states.

DiNardo (1993) investigates the relationship between law enforcement and the price of cocaine using U.S. data from the System to Retrieve Information from Drug Evidence (STRIDE) collected by the Drug Enforcement Agency (DEA) and finds no significant evidence supporting the hypothesis that increased law enforcement is associated with higher prices and, therefore, with lower consumption of illegal drugs. Poret (2003) constructs a model of a vertically organized distribution of illicit drugs to show that the results of stronger law enforcement can be opposite to the desired ones, namely, the decrease in consumption of illicit drugs. This model helps to explain the failure of the "war on drugs" declared in the U.S. in the 1980s. This tougher law enforcement was not associated with either reduced supply or lower prices. According to Reuter (1997), "this failure of cocaine and heroin prices to rise with tougher enforcement is a major analytic and policy puzzle".

Concerning the Portuguese decriminalization of illicit drugs, Hughes and Stevens 
(2010) advocate that it did not lead to higher drug use but did help to reduce the number of drug-related injuries, drug usage, and the criminal justice burden and costs. Greenwald (2009) suggests that the new Portuguese drug policy has been "a resounding success". The data show that drug usage, the number of drug-related deaths, and the number of HIV and AIDS infected individuals among drug addicts decreased substantially in the post-decriminalization period. Meanwhile, a great deal of financial resources were allocated to treatment and prevention through the Commissions for Dissuasion of Drug Addiction. Tavares and Portugal (2012) find that the Portuguese decriminalization of drugs contributed to improve drug-related outcomes, namely, the number of offenses and drug-related deaths.

Becker and Murphy (2013) argue that an alternative to the "war on drugs" policy declared by the U.S. is to follow Portugal's lead and decriminalize drug use while maintaining drug trafficking illegal. The decriminalization of drug use would reduce U.S. prison population since drug users cannot be criminally punished while promoting treatment of drug addicts.

The literature examines the trends in relevant outcome variables before and after the policy change and extends the analysis to countries with comparable characteristics. However, further empirical analysis is crucial to understand the degree of success of the Portuguese drug decriminalization. The current study introduces two main novelties in the analysis of this topic. To the best of our knowledge this is the first study that focuses on the supply side of the illicit drug market and attempts to accurately investigate a causal relationship between drug decriminalization and the evolution of drug prices. Second, we use a difference-in-differences model with additional control variables that allows us to account for unobserved country-specific characteristics and time effects.

\section{An accounting framework}

We start by presenting a simple theoretical model that helps to better understand the estimation strategy we follow in this study. DiNardo (1993) develops a theoretical model to study the relationship between law enforcement and the price and use of cocaine. In this section we closely follow the model formulated in his study. 
Consider the following demand function for illicit drugs in country $i$ at time $t$,

$$
q_{i t}^{d}=\beta \log (p)+\phi Z
$$

where $q_{i t}^{d}$ represents the demanded quantity of illicit drugs, $\log (p)$ is the logarithm of the price of illicit drugs, and $Z$ includes other factors that may also influence the demand for illicit drugs. According to the rational addiction theory proposed by Becker and Murphy (1988) the coefficient $\beta$ should be negative, as it measures the response of the demand of illicit drugs to changes in prices.

The supply function can be written in an analogous fashion

$$
q_{i t}^{s}=\gamma \log (p)+\delta X
$$

where $q_{i t}^{s}$ represents the supplied quantity of illicit drugs and $X$ is a vector of potential covariates influencing the supply of illicit drugs. Therefore, $X$ includes the policy change, which is the variable of primary interest in our study. Since we expect the quantity of supply to increase when prices increase, the coefficient $\gamma$ is expected to be positive. As mentioned above, one of the main speculative arguments against policy changes associated with liberalization of illicit drugs is the increased consumption triggered by lower prices. Therefore, decreased law enforcement would be associated with lower prices and higher consumption, and the coefficient $\delta$ on (2) should be positive.

The equilibrium in the illicit drugs market is described by the following condition

$$
q_{i t}^{d}=q_{i t}^{s}
$$

For simplicity of exposition we assume that $X$ is a single factor and $\phi=0$ as exclusion restriction, meaning that the impact of the policy change on the demand for illicit drugs works mainly through its impact on the supply of illicit drugs. This is consistent with the hypothesis that the impact of the policy change on the illicit drugs market is primarily related with its impact on the prices and availability of drugs.

Solving (2) for the logarithm of prices we obtain

$$
\log (p)=\frac{-\delta}{\gamma} X+\frac{1}{\gamma} q_{i t}^{s}
$$


If we substitute (4) back into (1), using (3), we obtain the reduced form equations:

$$
\begin{gathered}
q=\frac{-\delta \beta}{\gamma-\beta} X=\Pi_{q} X \\
\log (p)=\frac{-\delta}{\gamma-\beta} X=\Pi_{p} X .
\end{gathered}
$$

According to the main arguments in the theoretical studies on the impact of softer drug enforcement on prices and quantities, the reduced form coefficient on $X, \Pi_{q}$, is expected to be positive since $\beta<0, \gamma>0$, and $\delta>0$. Decreased law enforcement is associated with greater availability of drugs and reduced prices, which leads to higher illicit drugs use. Therefore, illicit drugs use is hypothesized to be positively associated with the policy change.

We can interpret (6) similarly. According to the above intuitive explanation, the policy change would contribute to increase the availability of illicit drugs and to decrease its price. The reduced form coefficient on $X, \Pi_{p}$, is expected to be negative if the hypothesis underlying the discussion on illicit drugs liberalization policies is empiric-evidence based.

In this study we perform a partial equilibrium analysis based on the reduced-form equations. We focus on the effects of the policy change that occurred in Portugal in 2001 on prices.

\section{Empirical Methodology and Data}

\subsection{Data Description}

We use a panel of 16 countries, including 15 European Union countries plus Norway, for the period between 1990 and 2010. We consider 2010 as the treatment year since, even though the decriminalization of use and possession of illicit drugs in Portugal entered into force on 1 July 2001, authorities started to apply the recommendations proposed by the National Strategy for the Fight Against Drugs before the legislative change. Therefore, we have 10 periods in the pre-treatment period and 11 periods in the post-treatment period. We study the impact of drug decriminalization on the retail prices of opiates and cocaine. 
The illegal nature of the illicit drugs market explains the scarce data available and the difficulty in understanding how data were collected and how reliable they are. The information on prices was obtained from the United Nations World Drug Report (2012) and refers to the retail prices (street prices) measured in US\$ per gram. The data source for drug prices for the European countries is the Annual Reports Questionnaire developed by the Commission on Narcotic Drugs and is complemented with information from the European Monitoring Center for Drugs and Drug Addiction (EMCDDA) and Europol. The EMCDDA data on prices come from different sources (police sources and surveys among drug users) and as a result, caution is required when using the data since the cross-country comparability may be compromised.

We follow Abadie, Diamond, and Hainmueller (2010) and include a set of control variables used to characterize the demographic, social, and economic environments of a country. The control variables used in the analysis are the (logarithm of) GDP per capita, the proportion of population aged from 15 to 24 years old, alcohol consumption, and the (logarithm of) number of seizures. The first two variables are intended to characterize the economic context, whereas the third is used to measure the importance of young population in the population structure. Alcohol consumption is also included in the estimation since it is sometimes referred to as a substitute for drug use and is often associated with drug environments. The control variable pertaining to seizures is understood as an indicator of the size of market supply.

A detailed description of the variables and sources is in Appendix Table A1.

\subsection{Difference-in-Differences Estimator}

The empirical model that we use to analyze the impact of drug decriminalization on illicit drugs prices is a difference-in-differences (DID) model with controls for country observed and unobserved heterogeneity and for time effects that are assumed in the baseline model to be common across countries.

Consider the following model specifications:

$$
\log y_{i t}=\alpha_{i}+\lambda t+\beta \text { Port }_{i}+\gamma \mathrm{DU}_{t}+\delta \text { Port }_{i} * \text { After }_{t}+\mathbf{x}_{i t}^{\prime} \beta+\varepsilon_{i t}
$$

and 


$$
\log y_{i t}=\alpha_{i}+\lambda t+\beta \text { Port }_{i}+\gamma \mathrm{DT}_{t}+\delta \text { Port }_{i} * \text { Spline }_{t}+\mathbf{x}_{i t}^{\prime} \beta+\varepsilon_{i t}
$$

where $i=1, \ldots, N$ designates each country in the sample and the subscript $t$ designates time. Port ${ }_{i}$ is an indicator variable for the treatment group, Portugal, and After $_{t}$ is a dummy variable for time equal to one in the post-treatment period. The variable Spline $_{t}$ is defined as equal to zero in the pre-treatment period and equal to $(t-1999)$ in the post-treatment period. The parameter $\delta$ is the one of main interest and measures the treatment effect. The dependent variable $\ln y_{i t}$ represents two possible outcomes: (the logarithm of) opiates and cocaine prices. The vector $\mathbf{x}_{i t}$ comprehends a set of time-varying observable individual characteristics and $\beta$ is a vector of coefficients. The term $\alpha_{i}$ denotes a full set of country dummy variables, $t$ is a linear time trend and $\varepsilon_{i t}$ is a zero mean disturbance term capturing all other omitted factors.

The model specification formulated in (7) accounts for a level shift in the price of drugs implied by the drug decriminalization policy while the model in (8) seeks to detect whether there was a shift in the slope of the price series.

Estimation of the model presented above can be done using standard estimation methods to deal with the presence of individual-specific effects. Wooldridge (2002) suggests estimation of this model applying the within estimator, provided that the policy change is strictly exogenous.

One of the most common problems associated with the difference-in-differences estimation is the presence of an individual-specific time trend, so that the treatment and the control groups follow different time trends. If that is the case, the differencein-differences estimator can be biased. According to the series plotted in Figures 1 and 2 it seems reasonable to assume that there are no systematic differences in the time trends between the two groups in the pre-treatment period. In order to fully account for the possibility of unobserved temporary individual-specific effects we estimate our baseline model using country-specific time trends. In this case, the estimated models are given by the following equations:

$$
\log y_{i t}=\alpha_{i}+\lambda_{i} t+\beta \text { Port }_{i}+\gamma \text { After }_{t}+\delta \text { Port }_{i} * \text { After }_{t}+\mathbf{x}_{i t}^{\prime} \beta+\varepsilon_{i t}
$$

and 


$$
\log y_{i t}=\alpha_{i}+\lambda_{i} t+\beta \text { Port }_{i}+\gamma \text { Spline }_{t}+\delta \text { Port }_{i} * \text { Spline }_{t}+\mathbf{x}_{i t}^{\prime} \beta+\varepsilon_{i t}
$$

where $\lambda_{i}$ represents a country-specific time trend.

\subsubsection{Results}

The estimation results based on the model specifications defined in equations (7) and (8) are reported in Tables 1 and 2. The former presents the results concerning the prices of opiates and the latter the prices of cocaine. All columns report fixed-effects estimates controlling for differential trends. Columns (1), (2), and (3) report fixedeffects estimates using a common time trend while the estimates in columns (4) and (5) were obtained considering a country-specific time trend.

According to the estimates in columns (1) and (2) in Table 1 we can conclude that the treatment effect, measured by the parameter $\delta$, is positive and statistically significant, meaning that the prices of opiates are higher in Portugal than they would be in the absence of the drug decriminalization policy. Given the results in column (2), prices of opiates in Portugal are on average $38.2 \%$ higher than they would be in the absence of the policy change, keeping all other factors constant. The estimates reported in columns (3), (4), and (5) regarding the impact of the drug decriminalization policy on the price of opiates suggest that the treatment effect is positive but not statistically significant. We find no evidence for a slope change in the trend of the prices of opiates.

Concerning the impact of the policy change on the price of cocaine, the results in columns (1), (2), and (3) of Table 2 suggest that the treatment effect is positive and statistically significant. Again, if anything, the drug decriminalization policy contributed to higher prices.

These results suggest that the treatment effect is positive meaning that the prices of opiates and cocaine were higher than they would have been in the absence of the policy change and contrast with the common fear regarding lower prices characterizing the debates about drug deregulation. They show that in the case of Portugal, systematic differences can be found in the prices of opiates and cocaine. 
Table 1 - Effect of drug decriminalization on prices of opiates

\begin{tabular}{|c|c|c|c|c|c|}
\hline & \multicolumn{5}{|c|}{ Prices of Opiates } \\
\hline & $(1)$ & $(2)$ & $(3)$ & $(4)$ & $(5)$ \\
\hline After & $\begin{array}{c}-0.240^{* *} \\
(0.086)\end{array}$ & $\begin{array}{c}-0.288^{* *} \\
(0.117)\end{array}$ & & & \\
\hline After*Port & $\begin{array}{c}0.191^{* *} \\
(0.068)\end{array}$ & $\begin{array}{c}0.382^{* *} \\
(0.149)\end{array}$ & & $\begin{array}{c}0.136 \\
(0.090)\end{array}$ & \\
\hline Spline & & & $\begin{array}{c}0.095^{* * *} \\
(0.019)\end{array}$ & & \\
\hline Spline*Port & & & $\begin{array}{c}0.034 \\
(0.020)\end{array}$ & & $\begin{array}{c}0.029 \\
(0.048)\end{array}$ \\
\hline Alcohol Consumption & & $\begin{array}{c}0.057 \\
(0.041)\end{array}$ & $\begin{array}{c}0.0009 \\
(0.035)\end{array}$ & $\begin{array}{c}0.031 \\
(0.078)\end{array}$ & $\begin{array}{c}0.026 \\
(0.082)\end{array}$ \\
\hline Young Population & & $\begin{array}{c}0.063 \\
(0.040)\end{array}$ & $\begin{array}{c}0.032 \\
(0.036)\end{array}$ & $\begin{array}{l}0.109^{*} \\
(0.061)\end{array}$ & $\begin{array}{c}0.112 \\
(0.066)\end{array}$ \\
\hline Log GDP per capita & & $\begin{array}{c}-1.667^{*} \\
(0.846)\end{array}$ & $\begin{array}{l}-1.045 \\
(0.671)\end{array}$ & $\begin{array}{c}-4.241^{* * *} \\
(1.250)\end{array}$ & $\begin{array}{c}-4.058^{* *} \\
(1.389)\end{array}$ \\
\hline Log Heroin Seizures & & $\begin{array}{l}-0.025 \\
(0.038)\end{array}$ & $\begin{array}{c}0.043 \\
(0.030)\end{array}$ & $\begin{array}{c}-0.009 \\
(0.050)\end{array}$ & $\begin{array}{c}-0.009 \\
(0.051)\end{array}$ \\
\hline Observations & 285 & 248 & 248 & 248 & 248 \\
\hline Adjusted $R^{2}$ & 0.348 & 0.381 & 0.426 & 0.469 & 0.469 \\
\hline Common Time Trend & Yes & Yes & Yes & No & No \\
\hline Country-Specific Time Trend & No & No & No & Yes & Yes \\
\hline Country Dummies & Yes & Yes & Yes & Yes & Yes \\
\hline
\end{tabular}

Notes: The dependent variable is the logarithm of opiates prices. The sampling period goes from 1990 to 2010. The variables alcohol consumption, percentage of young population, (logarithm of) number of drug seizures, and (logarithm of) GDP per capita are introduced as control variables in columns (2), (3), (4), and (5). A common time trend is included in columns (1), (2), and (3) and a country-specific time trend is considered in columns (4) and (5). Fixed effects estimates with robust standard errors clustered at country level in parentheses. ${ }^{*} p<0.1,{ }^{* *} p<0.05$, ${ }^{* * *} p<0.01$. Detailed data definitions and sources given in the appendix. 
Table 2 - Effect of drug decriminalization on prices of cocaine

\begin{tabular}{|c|c|c|c|c|c|}
\hline & \multicolumn{5}{|c|}{ Prices of Cocaine } \\
\hline & $(1)$ & $(2)$ & $(3)$ & $(4)$ & $(5)$ \\
\hline After & $\begin{array}{c}-0.166^{* * *} \\
(0.031)\end{array}$ & $\begin{array}{c}-0.160^{* * *} \\
(0.036)\end{array}$ & & & \\
\hline After*Port & $\begin{array}{c}0.125^{* * *} \\
(0.028)\end{array}$ & $\begin{array}{c}0.253^{* * *} \\
(0.070)\end{array}$ & & $\begin{array}{c}0.066 \\
(0.045)\end{array}$ & \\
\hline Spline & & & $\begin{array}{c}0.052^{* * *} \\
(0.017)\end{array}$ & & \\
\hline Spline*Port & & & $\begin{array}{c}0.021^{*} \\
(0.011)\end{array}$ & & $\begin{array}{c}0.033 \\
(0.027)\end{array}$ \\
\hline Alcohol Consumption & & $\begin{array}{c}0.056^{* *} \\
(0.023)\end{array}$ & $\begin{array}{c}0.016 \\
(0.018)\end{array}$ & $\begin{array}{l}0.076^{*} \\
(0.036)\end{array}$ & $\begin{array}{c}0.071^{*} \\
(0.038)\end{array}$ \\
\hline Young Population & & $\begin{array}{c}-0.003 \\
(0.026)\end{array}$ & $\begin{array}{l}-0.015 \\
(0.024)\end{array}$ & $\begin{array}{c}0.054 \\
(0.040)\end{array}$ & $\begin{array}{c}0.058 \\
(0.038)\end{array}$ \\
\hline Log GDP per capita & & $\begin{array}{c}-1.272^{* *} \\
(0.551)\end{array}$ & $\begin{array}{r}-0.796^{*} \\
(0.407)\end{array}$ & $\begin{array}{c}-1.281^{*} \\
(0.689)\end{array}$ & $\begin{array}{l}-1.097 \\
(0.735)\end{array}$ \\
\hline Log Cocaine Seizures & & $\begin{array}{c}0.045^{* *} \\
(0.019) \\
\end{array}$ & $\begin{array}{c}0.064^{* * * *} \\
(0.021)\end{array}$ & $\begin{array}{c}0.057 \\
(0.035) \\
\end{array}$ & $\begin{array}{c}0.059 \\
(0.037)\end{array}$ \\
\hline Observations & 285 & 245 & 245 & 245 & 245 \\
\hline Adjusted $R^{2}$ & 0.258 & 0.364 & 0.419 & 0.437 & 0.439 \\
\hline Common Time Trend & Yes & Yes & Yes & No & No \\
\hline Country-Specific Time Trend & No & No & No & Yes & Yes \\
\hline Country Dummies & Yes & Yes & Yes & Yes & Yes \\
\hline
\end{tabular}

Notes: The dependent variable is the logarithm of cocaine prices. The sampling period goes from 1990 to 2010. The variables alcohol consumption, percentage of young population, (logarithm of) number of drug seizures, and (logarithm of) GDP per capita are introduced as control variables in columns (2), (3), (4), and (5). A common time trend is included in columns (1), (2), and (3) and a country-specific time trend is considered in columns (4) and (5). Fixed effects estimates with robust standard errors clustered at country level in parentheses. ${ }^{*} p<0.1,{ }^{* *} p<0.05$, ${ }^{* * *} p<0.01$. Detailed data definitions and sources given in the appendix. 


\subsection{Synthetic Control Method}

In this section we apply the synthetic control method (SCM) proposed by Abadie and Gardeazabal (2003) and Abadie, Diamond, and Hainmueller (2010). This method allows for the construction of a "synthetic" control region, which is a convex combination of countries that best resemble the relevant economic and social characteristics of Portugal before the implementation of the drug decriminalization policy in 2001. It is then possible to compare the evolution of prices of cocaine and opiates between Portugal and the "counterfactual" Portugal.

This comparative case study method addresses the problem of subjective comparison group selection by using a data-driven procedure to construct suitable comparison groups. The comparison group will be a weighted combination of the potential comparison countries obtained using observable and measurable characteristics. According to this method, the characteristics of the treated unit before the treatment period can be better approximated by a combination of comparison units than by any comparison unit alone.

An important advantage of the SCM relative to the standard difference-in-differences estimation method is that it accommodates the possibility of time-varying unobservable heterogeneity. Also, the SCM makes explicit the relative contribution of each potential comparison country to the counterfactual of interest, and the similarities between the country of interest and the set of available control countries.

\subsubsection{How to construct the synthetic control group}

To summarize the SCM we closely follow Abadie, Diamond, and Hainmueller (2012). Let $J$ denote the number of available control units comprising the "donor pool" and consider, without loss of generality, that only one unit is exposed to treatment, so that we have a sample of $J+1$ units. Assume that the dataset is a balanced panel spanning $T$ time periods and that the sample includes $T_{0}$ pre-intervention periods and $T_{1}$ post-intervention periods, with $T_{0}+T_{1}=T$.

Then the synthetic group is defined as a weighted average of the available units in the donor pool. Consider a $(J \times 1)$ vector of weights $W=\left(w_{2}, \ldots, w_{J+1}\right)^{\prime}$, such that $0 \geq w_{j} \geq 1$ for $j=2, \ldots, J$ and $w_{2}+\ldots+w_{J+1}=1$. Each vector $\mathbf{W}$ represents a potential synthetic control for the treated unit. The authors propose to choose the 
value of $\mathbf{W}$ based on the observation of the characteristics of the treated unit that are best approximated by the characteristics of the synthetic control. Let $X_{1}$ be a $(k \times 1)$ vector of pre-treatment characteristics $k$ for the treated unit, and let $X_{0}$ be the $(k \times J)$ matrix with the values of the same $k$ variables for the $J$ control units in the donor pool. Then, the vector $X_{1}-X_{0} W$ summarizes the differences between the pre-intervention characteristics of the treated unit and the synthetic control, and $W^{*}$ is chosen to minimize this difference ${ }^{2}$.

Let $Y_{j t}$ denote the outcome of unit $j$ at time $t, Y_{1}$ the $\left(T_{1} \times 1\right)$ vector of posttreatment information for the treated unit, that is $\left(Y_{1 T_{0}+1}, \ldots, Y_{1 T}\right)^{\prime}$, and $Y_{0}$ the $\left(T_{1} \times J\right)$ matrix that contains the post-intervention values for the control units. The SCM aims to estimate the effect of the treatment $Y_{1}-Y_{0} W^{*}$, that is, the difference between the post-intervention outcomes between the treated unit and the synthetic control. Then, for $t \in\left\{T_{0+1}, . ., T\right\}$ the SCM estimator:

$$
Y_{1 T}-\sum_{j=2}^{J+1} w_{j}^{*} Y_{j t}
$$

gives the treatment effect as a difference between the outcome for the treated unit and the outcome for the synthetic control obtained as a convex combination of units in the donor pool.

Abadie and Gardeazabal (2003) argue that this factor model allows controlling for time-varying unobserved heterogeneity affecting either the outcome of interest or the effect of the determinants on the outcome of interest. The reasoning goes as follows: if the synthetic control unit is able to closely resemble the behavior of the treatment unit in the period before the intervention, then differences in the outcome variable between the treatment unit and the synthetic control unit after the treatment can be interpreted as a result of the treatment itself.

\subsubsection{Results}

The outcomes of interest are the prices of opiates and cocaine. The predictors of illicit drugs prices considered in the analysis for Portugal and the 14 potential control

\footnotetext{
${ }^{2} \mathrm{~A}$ more formal and detailed description can be found in Abadie and Gardeazabal (2003) and Abadie, Diamond, and Hainmueller (2010).
} 
countries in the donor pool, $X_{1}$ and $X_{0}$, respectively, include alcohol consumption, the proportion of young population, and the logarithm of GDP per capita. These variables are averaged over the period from 1990 to 1999 and augmented by adding three lagged illicit drug prices (1990, 1995, and 2000). This allows for a better fit of the synthetic control group.

Using the techniques described above we analyze the impact of the drug decriminalization policy followed by Portugal on the prices of opiates and cocaine. The synthetic counterfactual is obtained from a convex combination of the available countries in the donor pool as explained above.

The results regarding the predictors of prices are shown in Table A4 and reveal a close fit between Portugal and the synthetic counterpart. The weights of each country in the donor pool in the synthetic Portugal are in Table A3 and indicate that the pretreatment Portugal is best resembled by a convex combination of France, Germany, Italy, and Netherlands regarding the price of opiates, and Belgium and Netherlands regarding the price of cocaine. Zero or almost zero weights are assigned to the other donor pool countries.

Figures 3 and 4 show the trends in the prices for Portugal and the synthetic Portugal for the period between 1990 and 2010, respectively. We can see that the synthetic Portugal closely resembles Portugal in the pre-treatment period. The results suggest that no major divergence between Portugal and the synthetic counterpart can be found after the implementation of the drug decriminalization policy in 2000 .

Figures 5 and 6 depict the yearly gaps in the prices between Portugal and the synthetic Portugal. They suggest that, if anything, the treatment effect seems to be positive, meaning that prices were on average higher than the ones that would have been charged in the absence of the drug decriminalization policy.

Therefore, this study enlightens the discussion of alternative forms of drug liberalization and counters the belief that drug decriminalization necessarily leads to lower drug prices and, consequently, to greater drug consumption.

The assessment of the key outcomes allows us to say that treating users while harassing drug dealers and traffickers seems to be an effective policy. 


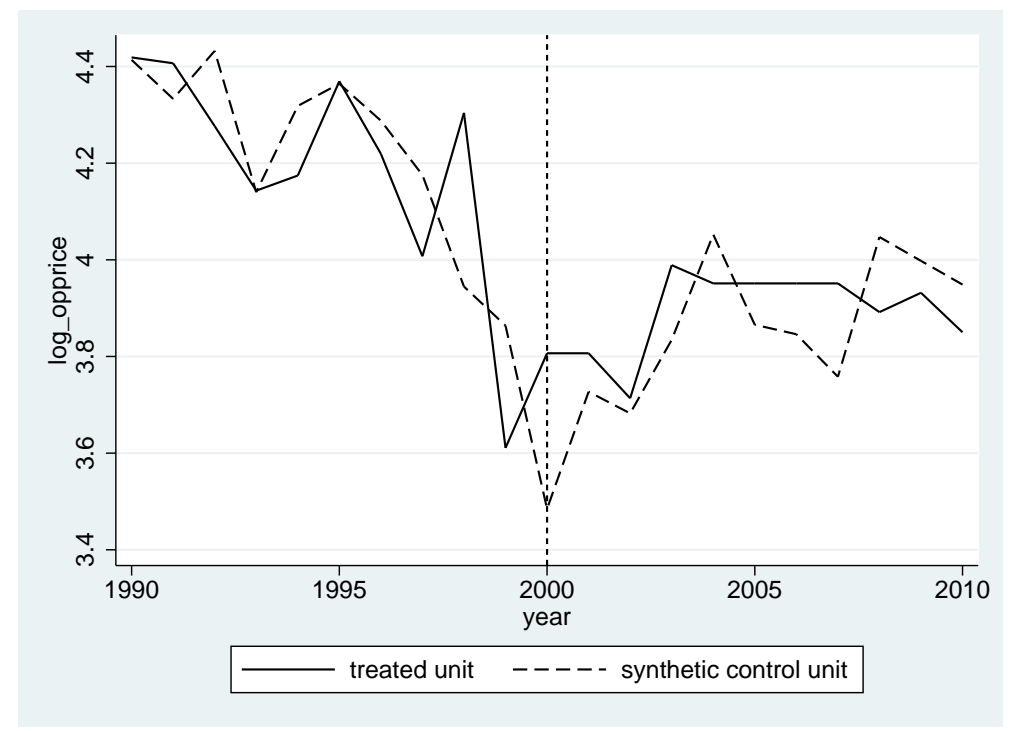

Figure 3 - Trends in the logarithm of opiates prices: Portugal vs. Synthetic Portugal Notes: The synthetic Portugal is obtained through a convex combination of Austria (0.001), Belgium (0.004), France (0.186), Germany (0.257), Ireland (0.001), Italy (0.096), Netherlands (0.450), Spain (0.003), and United Kingdom (0.001). For detailed data definitions and sources see Appendix Table A1.

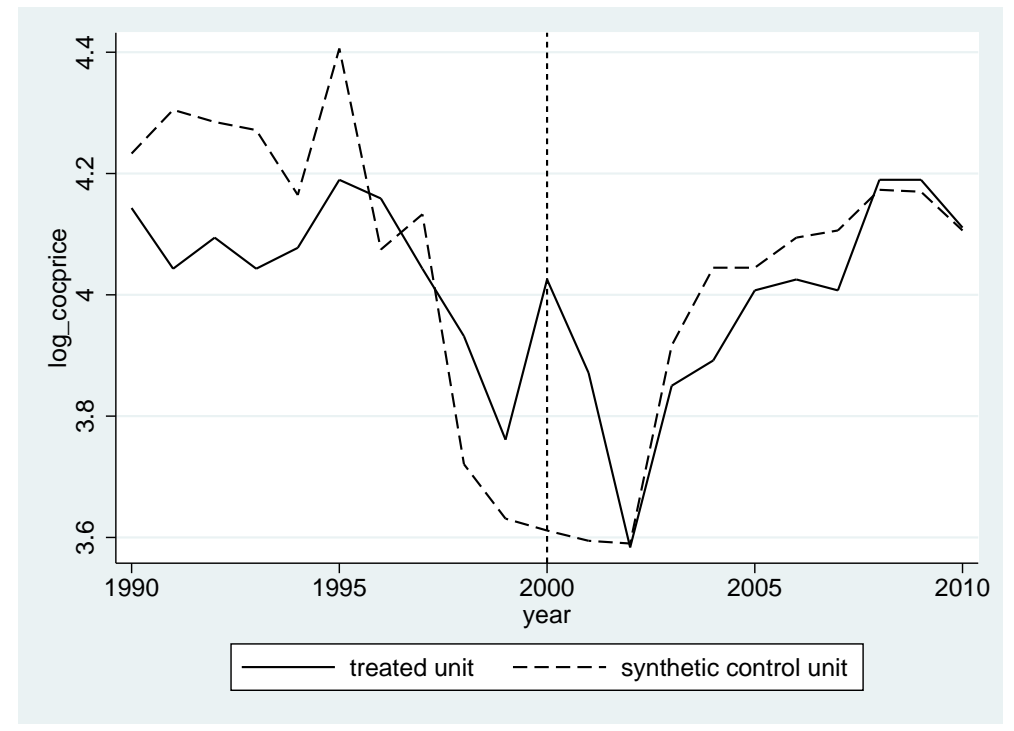

Figure 4 - Trends in the logarithm of cocaine prices: Portugal vs. Synthetic Portugal Notes: The synthetic Portugal is obtained through a convex combination of Belgium (0.225) and Netherlands (0.775). For detailed data definitions and sources see Appendix Table A1. 


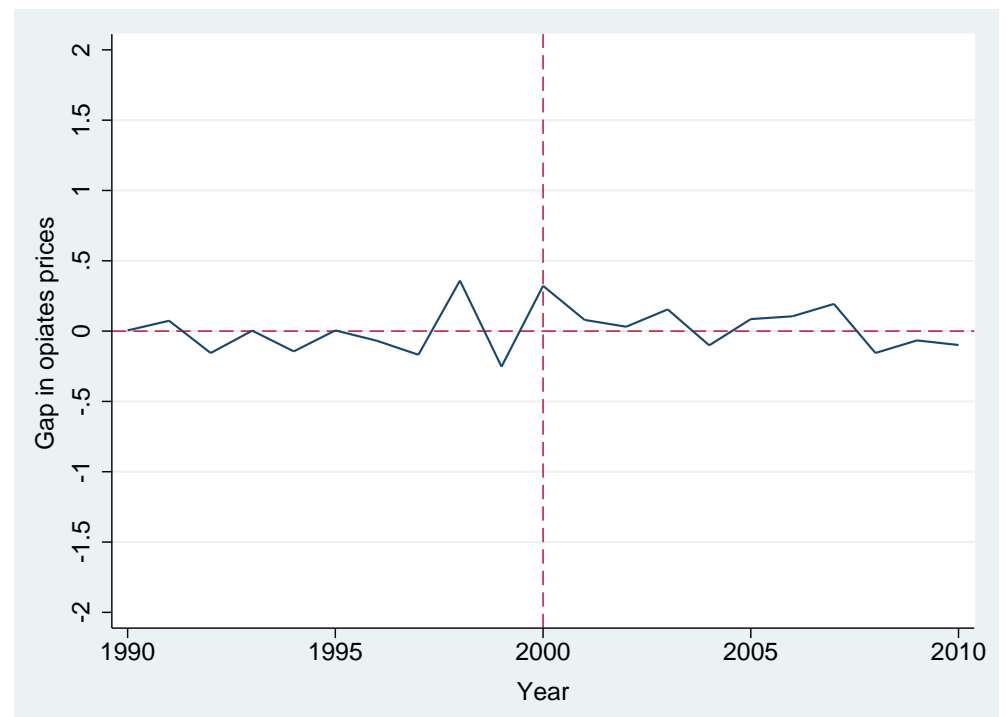

Figure 5 - Logarithm of opiates prices gap between Portugal and Synthetic Portugal Notes: For detailed data definitions and sources see Appendix Table A1.

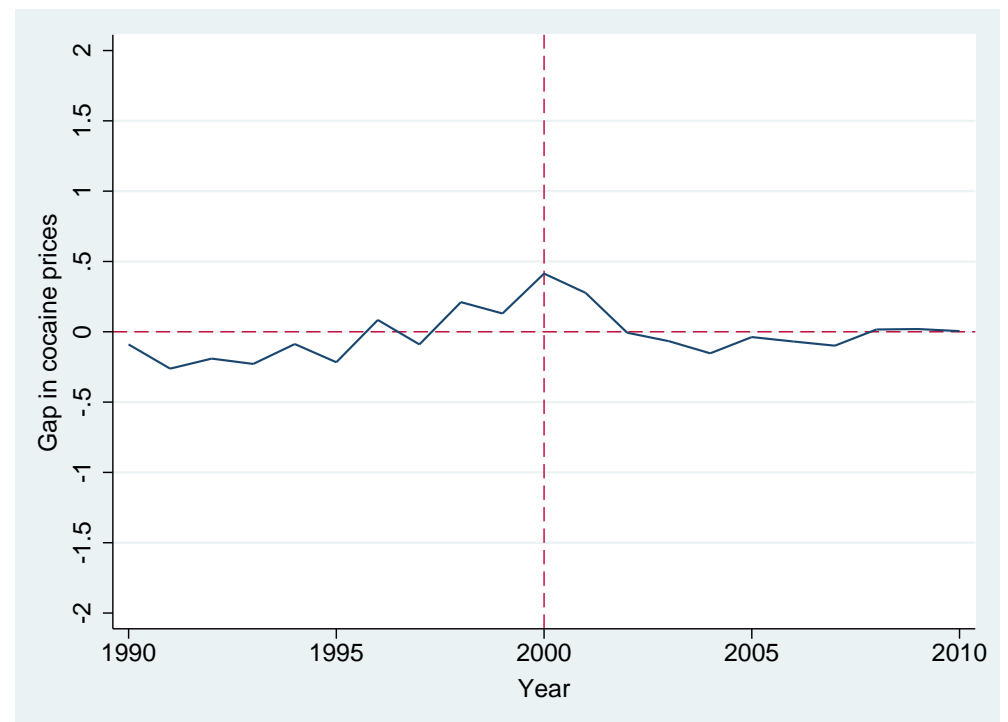

Figure 6 - Logarithm of cocaine prices gap between Portugal and Synthetic Portugal Notes: For detailed data definitions and sources see Appendix Table A1.

\subsubsection{Inference using SCM}

The SCM does not allow us to use standard statistical inferences to assess the statistical significance of the estimated coefficients as the number of units in the comparison 
group are usually small. However, Abadie and Gardeazabal (2003) propose using falsification tests, which the authors call "placebo studies", to perform alternative quantitative inference. The idea is to apply the SCM to each country in the donor pool (akin to permutation tests) and see if the estimated effect in the treatment unit is of greater magnitude relative to the units where intervention did not take place. If those (false) treatment effects are of similar or greater magnitude as the estimated effect for the treated unit, then our results could be compromised.

The results of the placebo studies are shown in Figures 7 and 8.

When the drug policy change is artificially and randomly assigned to countries in the donor pool where the drug policy did not in fact change, we find estimates of larger or similar magnitude to the ones obtained for Portugal. This evidence is consistent with the lack of systematic differences in the trends of opiates and cocaine prices for Portugal and its synthetic counterpart after the 2001 drug decriminalization policy.

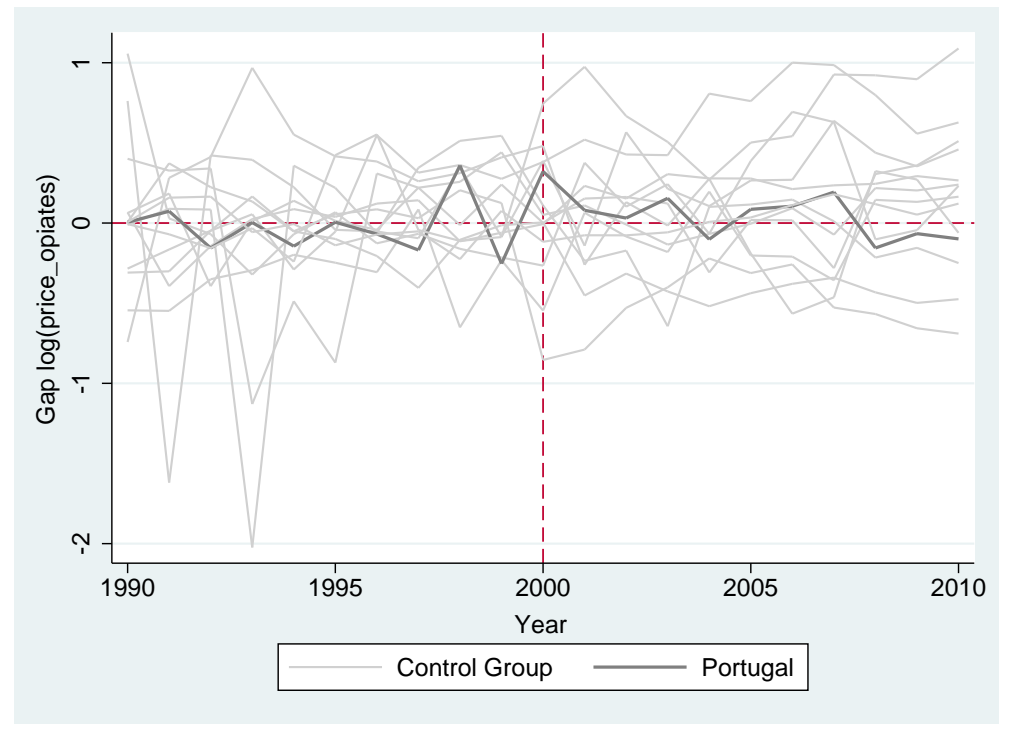

Figure 7 - Logarithm of opiates prices gaps in Portugal and placebo gaps in the control countries

Notes: For detailed data definitions and sources see Appendix Table A1. 


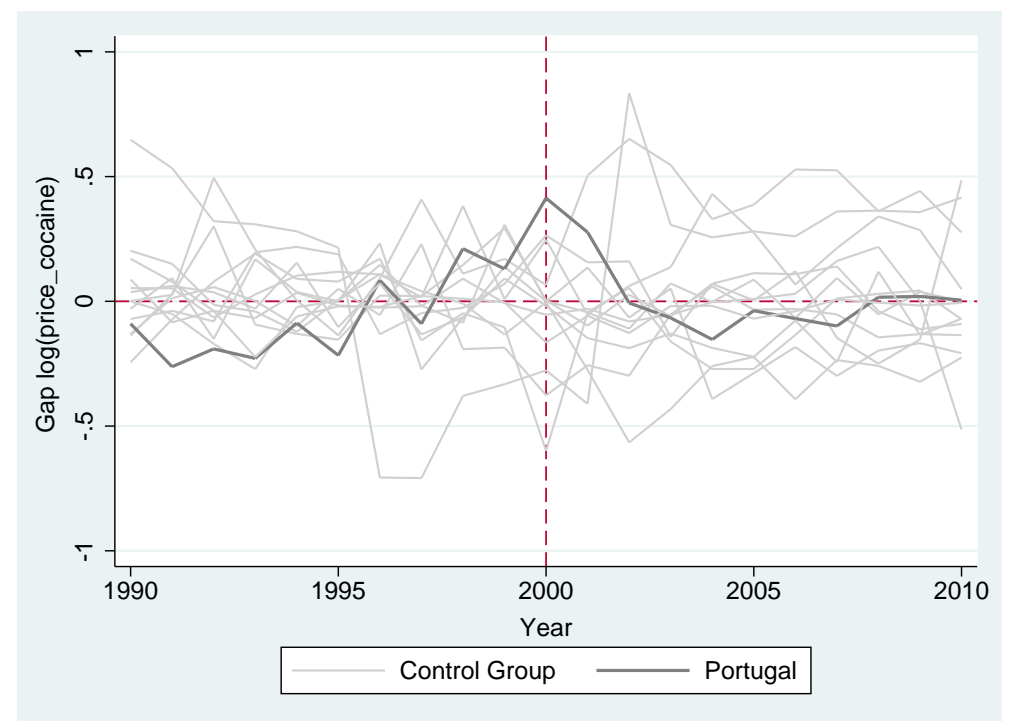

Figure 8 - Logarithm of cocaine prices gaps in Portugal and placebo gaps in the control countries

Notes: For detailed data definitions and sources see Appendix Table A1.

\section{Conclusions}

The existing forms of drug liberalization have been hotly debated over the past years in several countries, especially in the United Kingdom. However, the public debate is couched mostly in speculation, due to the lack of empirical evidence on these matters.

In this study we recognize the importance of drug demand indicators but we focus our analysis on the supply side. To the best of our knowledge this is the first study that investigates the role of the drug decriminalization process in illicit drug prices.

With this analysis we contribute to the drug policy debate by empirically assessing the impact of the Portuguese drug decriminalization (which occurred on 1 July 2001) on drug prices. We find that (retail) prices of cocaine and heroin did not decrease following the drug decriminalization. Therefore, drug decriminalization seems to have caused no harm through lower illicit drugs prices, which would lead to higher drug usage and dependence.

According to these results softer drug law enforcement regarding illicit drug consumers does not inevitably lead to lower prices. In the 1980s the United States started to pursue a harsher drug law enforcement by increasing sanctions associated 
with drug-related crime. During this period consumption did not decrease and contrary to expectations, street prices fell. Our results are in line with this failure of the "war on drugs" to link higher prices with increased toughness. In the Portuguese case, decreased toughness did not contribute to lower prices but rather to higher prices than the ones that would be observed in the absence of drug decriminalization.

All in all, policy makers should not discard the drug decriminalization policy as a drug policy solution based on the apparently incorrect belief that illicit drugs prices will inevitably fall after the policy implementation. 


\section{References}

Abadie, A., A. Diamond, And J. Hainmueller (2010): "Synthetic Control Methods for Comparative Case Studies: Estimating the Effects of California's Tobacco Control Program," Journal of the American Statistical Association, 105, 493-505.

- (2012): "Comparative Politics and the Synthetic Control Method," MIT Political Science Research Paper No. 2011-25.

Abadie, A., And J. Gardeazabal (2003): "The Economic Costs of Conflict: A Case Study of the Basque Country," American Economic Review, 93(1), 114-132.

Becker, G. S., M. Grossman, And K. M. Murphy (1994): "An Empirical Analysis of Cigarette Addiction," American Economic Review, 84, 397-418.

Becker, G. S., And K. M. Murphy (1988): “A Theory of Rational Addiction,” Journal of Political Economy, 96, 675-700.

Becker, G. S., And K. M. Murphy (2013): "Have we lost the war on drugs?," Wall Street Journal - The Saturday Essay.

Caulkins, J. (1995): "Estimating the Elasticities and Cross Elasticities of Demand for Cocaine and Heroin," Heinz School Working Paper 95-13.

Coate, D., And M. Grossman (1988): "Effects of Alcohol Beverage Prices and Legal Drinking Ages on Youth Alcohol Use," Journal of Law and Economics, 31(1), 145-171.

Costa Storti, C., And P. De Grawve (2009a): "The cocaine and heroin markets in the era of globalisation and drug reduction policies," International Journal of Drug Policy, 20, 488-496.

(2009b): "Globalization and the price decline of illicit drugs," International Journal of Drug Policy, 20, 48-61.

Damrongplasit, K., C. Hsiao, and X. Zhao (2010): "Decriminalization and Marijuana Prevalence: Evidence from Australia," Journal of Business and Economics Statistics, 28, 344-359.

DiNardo, J. (1993): "Law Enforcement, the Price of Cocaine and Cocaine Use," Mathematical Computer Modelling, 17, 53-64.

Donnelly, N., W. Hall, And P. Christie (1995): "The Effects of Decriminalization on Cannabis Use in South Australia 1985-1993," Australian Journal of Public Health, 19, $281-7$.

Featherston, J., And S. Lenton (2007): Effects of the Western Australian Cannabis 
Infringement Notice Scheme on Public Attitudes, Knowledge and Use: Comparison of Pre- and Post-Change Data. Perth: National Drug Research Institute.

Greenwald, G. (2009): Drug Decriminalization in Portugal: Lessons for Creating Fair and Successful Drug Policies. CATO Institute Washington, DC.

Grossman, M., and F. J. Chaloupka (1998): "The Demand for Cocaine by Young Adults: A Rational Addiction Approach," Journal of Health Economics, 17, 427-474.

Hughes, C. E., And A. Stevens (2010): "What Can We Learn from the Portuguese Decriminalization of Illicit Drugs," British Journal of Criminology, 50, 999-1022.

Poret, S. (2003): "Paradoxical Effects of Law Enforcement Policies: The Case of the Illicit Drug Market," International Review of Law and Economics, 22, 465-493.

Reuter, P. (1997): "Why Can't We Make Prohibition Work Better?," Proceedings of the American Philosophical Society, 141, 262-275.

Saffer, H., And F. Chaloupka (1999): "The Demand for Illicit Drugs," Economic Inquiry, 37, 401-411.

Tavares, A., And P. Portugal (2012): "Going after the addition and not the addicted," mimeo.

VanOurs, J. C. (1995): "The Price Elasticity of Hard Drugs: The Case of Opium in the Dutch East Indies, 1923-1938," Journal of Political Economy, 103(2), 261-279.

Williams, J. (2004): "The Effects of Price and Policy on Marijuana Use: What Can Be Learned from the Australian Experience," Health Economics, 13, 123-37.

Wooldridge, J. M. (2002): Econometric Analysis of Cross Section and Panel Data. The MIT Press.

Zhao, X., And M. N. Harris (2004): "Demand for Marijuana, Alcohol and Tobacco: Participation, Levels of Consumption and Cross-Equation Correlations," Economic Record, 80. 
Table A1 Data description and sources

\begin{tabular}{|c|c|c|}
\hline Variable & Description & Source \\
\hline Price of Opiates & $\begin{array}{l}\text { Measured as the logarithm of the retail price } \\
\text { (street price) of opiates, US dollars per gram }\end{array}$ & UN World Drug Report (2009) \\
\hline Price of Cocaine & $\begin{array}{l}\text { Measured as the logarithm of the retail price } \\
\text { (street price) of cocaine, US dollars per gram }\end{array}$ & UN World Drug Report (2009) \\
\hline GDP per capita & $\begin{array}{l}\text { Measured as the logarithm of the constant } \\
2005 \text { GDP per capita measured in US dollars }\end{array}$ & $\begin{array}{l}\text { OECD (National Accounts } \\
\text { Data) }\end{array}$ \\
\hline $\begin{array}{l}\text { Unemployment } \\
\text { Rate }\end{array}$ & $\begin{array}{l}\text { Total unemployment as a percentage of total } \\
\text { labor force }\end{array}$ & $\begin{array}{l}\text { International Labor Organiza- } \\
\text { tion }\end{array}$ \\
\hline Young Population & $\begin{array}{l}\text { Proportion of population aged between } 15 \text { and } \\
24 \text { years old }\end{array}$ & EUROSTAT \\
\hline $\begin{array}{l}\text { Alcohol Consump- } \\
\text { tion }\end{array}$ & $\begin{array}{l}\text { Liters consumed per capita by individuals } \\
\text { aged above } 15 \text { years old }\end{array}$ & OECD Health Data \\
\hline Heroin Seizures & $\begin{array}{l}\text { Measured as the logarithm of the number of } \\
\text { heroin seizures by law enforcement agencies, } \\
\text { namely police, customs officials, and national } \\
\text { guard. }\end{array}$ & EMCDDA \\
\hline Cocaine Seizures & $\begin{array}{l}\text { Measured as the logarithm of the number of } \\
\text { cocaine seizures by law enforcement agencies, } \\
\text { namely police, customs officials, and national } \\
\text { guard. }\end{array}$ & EMCDDA \\
\hline
\end{tabular}

Table A2 Countries included in the sample

\begin{tabular}{l}
\hline Country \\
\hline Austria, Belgium, Denmark, Finland, France, Germany, Greece, Ireland, Italy, Luxembourg, \\
Netherlands, Norway, Portugal, Spain, Sweden, United Kingdom \\
\hline
\end{tabular}


Table A3 Country weights in the donor pool for Synthetic Portugal

\begin{tabular}{lcc}
\hline & Prices of Opiates & Prices of Cocaine \\
\hline Austria & 0.001 & 0.000 \\
Belgium & 0.004 & 0.225 \\
Denmark & 0.000 & 0.000 \\
Finland & 0.000 & 0.000 \\
France & 0.186 & 0.000 \\
Germany & 0.257 & 0.000 \\
Ireland & 0.001 & 0.000 \\
Italy & 0.096 & 0.000 \\
Luxembourg & 0.000 & 0.000 \\
Netherlands & 0.450 & 0.775 \\
Norway & 0.000 & 0.000 \\
Spain & 0.003 & 0.000 \\
Sweden & 0.000 & 0.000 \\
United Kingdom & 0.001 & 0.000 \\
\hline
\end{tabular}


Table A4 Predictor's balance for prices of opiates and prices of cocaine

\begin{tabular}{|c|c|c|c|c|}
\hline \multirow[b]{2}{*}{ Variables } & \multicolumn{2}{|c|}{ Prices of Opiates } & \multicolumn{2}{|c|}{ Prices of Cocaine } \\
\hline & Treated & $\overline{\text { Synthetic }}$ & Treated & Synthetic \\
\hline Alcohol Consumption & 14.63 & 11.31 & 14.63 & 10.19 \\
\hline Young Population & 15.96 & 13.43 & 15.96 & 13.60 \\
\hline Log GDP per capita & 9.79 & 10.21 & 9.79 & 10.25 \\
\hline Log Opiates Seizures & 7.89 & 7.88 & & \\
\hline Log Opiates Prices 2000 & 3.81 & 3.48 & & \\
\hline Log Opiates Prices 1995 & 4.37 & 4.36 & & \\
\hline Log Opiates Prices 1990 & 4.42 & 4.41 & & \\
\hline Log Cocaine Seizures & & & 6.67 & 7.21 \\
\hline Log Cocaine Prices 2000 & & & 4.03 & 3.61 \\
\hline Log Cocaine Prices 1995 & & & 4.19 & 4.41 \\
\hline Log Cocaine Prices 1990 & & & 4.14 & 4.23 \\
\hline RMSPE & \multicolumn{2}{|c|}{0.1674} & \multicolumn{2}{|c|}{0.1722} \\
\hline
\end{tabular}

Notes: All predictors are averaged for the period 1990 to 1999. Detailed data definition can be found in Appendix Table A1. The Root Mean Square Prediction Error (RMSPE) is a measure of goodness of fit and measures the fit between the trends of the outcome variable for Portugal and its synthetic counterpart. RMSPE $=\sqrt{\frac{1}{T_{0}} \sum_{t=1}^{T_{0}}\left(Y_{1 T}-\sum_{j=2}^{J+1} w_{j}^{*} Y_{j t}\right)^{2}}$. 